\title{
A comparative study of oral iron and intravenous iron in iron deficient antenatal mothers
}

\author{
Suganya G.*, D. Vimala
}

Department of Obstetrics and Gynecology, Vinayaka Mission Kirupanandha Variyar Medical College and Hospital, Salem, Tamil Nadu, India

Received: 03 March 2018

Accepted: 28 March 2018

*Correspondence:

Dr. Suganya G.,

E-mail: sugu199113@gmail.com

Copyright: (c) the author(s), publisher and licensee Medip Academy. This is an open-access article distributed under the terms of the Creative Commons Attribution Non-Commercial License, which permits unrestricted non-commercial use, distribution, and reproduction in any medium, provided the original work is properly cited.

\section{ABSTRACT}

Background: The aim of the study is to compare the efficacy, tolerance and compliance between oral iron and intravenous infusion of iron in iron deficient antenatal mother.

Methods: This is a prospective randomised clinical and interventional study in the department of Obstetrics and Gynaecology in Vinayaka Mission Kirupananda Variyar Medical College and Hospital. The antenatal women attending the antenatal op were screened for $\mathrm{Hb}$ status. Those antenatal women of gestational age 16-34 weeks with $\mathrm{Hb}$ level between $7-10 \mathrm{~g} \%$ and diagnosed to have iron deficiency anemia by peripheral smear and serum ferritin were included in this study after getting informed consent. The total numbers of 100 mothers were allotted into two major groups, group A and group B of 50 subjects each. Group A: 50 pregnant women given oral iron supplementation (carbonyl iron $100 \mathrm{mg}$ twice a day). Group B: 50 pregnant women given intravenous iron sucrose therapy after calculating the total iron requirement. The rise in hemoglobin in both the groups were compared

Results: In this study the mean rise of hemoglobin in carbonyl iron was $0.914 \pm 0.20 \mathrm{gm} \%$ whereas in iron sucrose group was $2.43 \pm 0.20 \mathrm{gm} \%$. This showed that iron sucrose (i.v) had better rise in $\mathrm{Hb}$ than carbonyl iron (oral).

Conclusions: The present study revealed that intravenous iron sucrose therapy was better

tolerated with higher increase in mean haemoglobin compared to oral iron therapy. There were no serious side effects with intravenous iron sucrose therapy. Intravenous iron sucrose is a good substitute to oral iron therapy in moderate anaemia.

Keywords: Antenatal mothers, Intravenous iron, Oral iron

\section{INTRODUCTION}

Anemia is estimated to affect $20-50 \%$ of the world's population and pregnancy is one of the most risk factors. The centre for disease control and prevention defines anemia when hemoglobin and hematocrit values are less than $11 \mathrm{~g} / \mathrm{dl}$ and $33 \%$ in the first and third trimester and $10.5 \mathrm{~g} / \mathrm{dl}$ and $32 \%$ in second trimester. ${ }^{1}$ Anemia is one of the world's leading problem.

Iron deficiency anemia is one of the common nutritional deficiency affecting pregnant females. According to national family health survey, incidence of anemia in pregnant women in India is 54\% in urban and 59\% in rural areas. It is responsible for adverse obstetric and perinatal outcome in a large number of women in developing countries.

Anemia is major public health concern in economically disadvantaged segments of population especially in developing countries. In a country like India, anemia is frequently severe and contributes to maternal mortality and morbidity. It deserves more attention than what it is currently receiving. Apart from economic backwardness, gender discrimination is more prevalent in India and other Asian countries. 
The girl child right from birth is neglected with regard to nutrition and education thereby leading to anaemia problem during school going age and pre pregnancy state itself.

There is increased incidence of blood transfusion and its risks in a woman in whom the anemia is not diagnosed in time and corrected properly. The incidence of anemia in India is $40-90 \%$. According to WHO anemia contributes to $40 \%$ of maternal deaths in third world countries. In India Maternal death due to anaemia is $10-15 \% .^{2}$

\section{METHODS}

This is a prospective randomised clinical and interventional study done in the Department of Obstetrics and Gynaecology, Vinayaka Missions Kirupananda Variyar Medical College and Hospitals, Salem, Tamilnadu for a period of 1 year from April 2016 to March 2017.

The antenatal women attending the antenatal OP were screened for Haemoglobin status. Those antenatal women of gestational age 16-34 weeks with haemoglobin between 7-10 gm\% were recruited in this study with informed consent. A total of hundred women were allotted into two major groups of 50 subjects each.

\section{Inclusion criteria}

Pregnant women with

- Iron deficiency anaemia with $\mathrm{Hb}$ values between 7$10 \mathrm{gm} \%$

- Gestational age 16-34 weeks.

- $\quad$ Single viable fetus with no anomalies.

\section{Exclusion criteria}

Pregnant women with

- Hb less than $7 \mathrm{gm} \%$ or more than $10 \mathrm{gm} \%$

- Gestational age less than 16 weeks and more than 34 weeks.

- Anaemia due to causes other than iron deficiency.

- History of blood transfusion and erythropoietin treatment in present pregnancy

- Other medical disorders complicating pregnancy or $\mathrm{h} / \mathrm{o}$ haematological diseases

- Multiple pregnancy

- Specific allergy to iron derivatives.

\section{Patient analysis}

Complete general physical examination was carried out along with examination of the cardiovascular system and respiratory system. Abdominal examination was carried out. Apart from routine antenatal profile, stools for ova, cyst and occult blood, serum ferritin (CLIA) were done and diagnosis of Iron deficiency anaemia confirmed. Haematological parameters were analysed. Initial blood examination was done between 16 and 34 weeks.

Following specific haematological investigations were done at the first visit other than routine investigations:

- Haemoglobin $(\mathrm{Hb})$

- Peripheral smear

The recruited pregnant women (100) were divided into two major groups and to make a. Comparative study with oral and parenteral iron therapy.

- Group A: 50 pregnant women given oral iron supplementation (carbonyl iron 100mg of elemental iron/day).

- Group B: 50 pregnant women given parenteral iron (iron sucrose) therapy after calculating iron requirement

\section{Calculation of patient's iron deficit}

Total iron dose required $(\mathrm{mg})=2.4 \mathrm{x}$ weight in $\mathrm{kg} \mathrm{x}$ target $\mathrm{Hb}-$ actual $\mathrm{Hb}$ of patient) $\mathrm{g} / \mathrm{dl}+500$

Final tests were done after 4 weeks of iron supplements in both groups.

\section{RESULTS}

In the age group 18-20yrs, 4, 1, 7 pregnant women had $\mathrm{Hb}$ rise of $0-0.9,1-1.9$ and $2-2.9$ gm\% respectively. In the age group 21-25 yrs, 14, 06, 20 pregnant women had a rise of $\mathrm{Hb}$ of $0-0.9,1-1.9,2-2.9$ gm\% respectively. In the age group 26-30 yrs, 17, 8, 21 pregnant women had $\mathrm{Hb}$ rise of $0-0.9,1-1.9,2-2.9 \mathrm{gm} \%$ respectively. Above $30 \mathrm{yrs}$ of age, pregnant women had a $\mathrm{Hb}$ rise of 2-2.9 gm\% respectively.

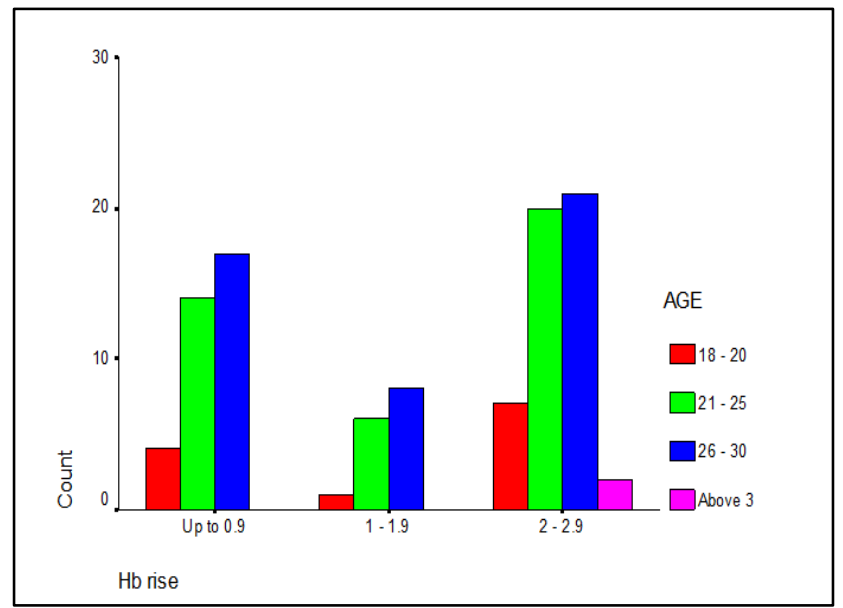

Figure 1: Comparison of rise in $\mathrm{HB}$ with distribution of age. 


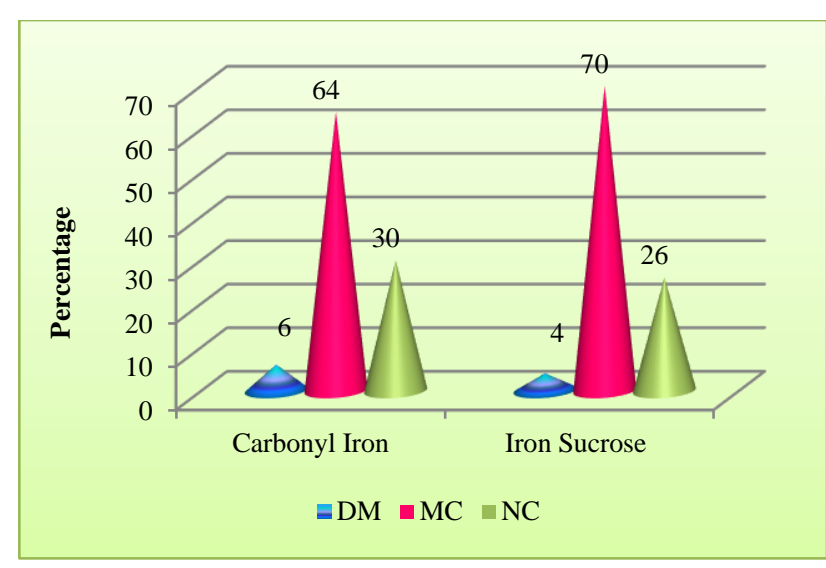

Figure 2: Distribution of patients according to type of peripheral smear (PS).

Figure 2 showing distribution of patients according to peripheral smear. Among these 64 to $70 \%$ were microcytic hypochromic, 26 to $30 \%$ showed normocytic normochromic and the $2-3 \%$ patients showed dimorphic anaemia which was found to be statistically insignificant between the groups.

Table 1: Adverse reactions.

\begin{tabular}{|ll|l|}
\hline Adverse reactions & IV group & Oral group \\
\hline Nausea/vomiting & 1 & 5 \\
\hline Epigastric pain & 0 & 0 \\
\hline Constipation & 0 & 2 \\
\hline Staining & 0 & 0 \\
\hline Thrombophlebitis & 0 & 0 \\
\hline Rashes & 2 & 0 \\
\hline Myalgia & 0 & 0 \\
\hline Fever & 0 & 0 \\
\hline Hypotension & 0 & 0 \\
\hline Total & 3 & 7 \\
\hline
\end{tabular}

Comparing both groups minimal adverse reactions are noted in oral group than intravenous group (IV). Tolerance and compliance are better with IV Group.

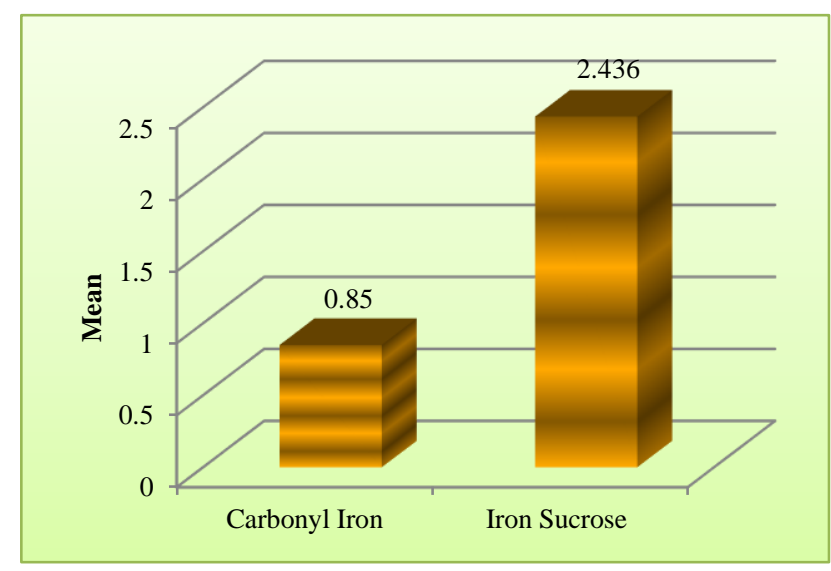

Figure 3: Comparison of carbonyl iron versus iron sucrose in rise of haemoglobin $(\mathrm{Hb})$.
Figure 3 comparing the above two drugs, the mean difference in $\mathrm{Hb}$ rise between Iron sucrose and Carbonyl iron is 1.586. The mean $\mathrm{Hb}$ rise for Iron sucrose and Carbonyl iron being $2.436 \pm 0.23$ and $0.850 \pm 0.16$ respectively. $\mathrm{P}$ value calculated $<0.001$ which is significant. Independent sample t-test is used.

\section{DISCUSSION}

Pregnant women (gestational age 16-34weeks) with moderate iron deficiency anaemia only ( $\mathrm{Hb} 7-10 \mathrm{gm} \%$ ) were recruited into the present study so as to ensure prevention of severe anaemia in these women at term by oral and intravenous therapy. Our study illustrates clearly that intravenous iron sucrose complex is effective with better compliance in efficacy and has a rapid and profound response in improving anaemia as compared to carbonyl Iron (oral therapy).

According to Malviya et al 2003, Singh et al $1998^{4}$ suggest a connection between age and the occurrence of anaemia since other studies have reported that young women ( $<18$ or $<20$ years) showed a higher tendency to be anaemic. ${ }^{1-3}$ In present study, the most affected (56 out of 100 women), by IDA in pregnancy were in the age group of 21-25 yrs.

There was no study conducted to report the $\mathrm{Hb}$ rise with only carbonyl iron in pregnant women. In our study, the mean haemoglobin rise was $0.91 \pm 0.20 \mathrm{gm} \%$ with carbonyl iron. In present study, the mean rise of $\mathrm{Hb}$ in carbonyl iron was $0.914 \pm 0.20 \mathrm{gm} \%$ whereas in iron sucrose group was $2.43 \pm 0.20 \mathrm{gm} \%$. This showed that iron sucrose (i.v) had better rise in $\mathrm{Hb}$ than carbonyl iron (oral).

A study was available - Wali A et al reported a better rise of $\mathrm{Hb}$ in iron sucrose group when compared to iron sorbitol. This showed that iron sucrose (i.v) therapy is better than iron sorbitol (i.m) therapy in treating IDA in pregnancy.

In present study, while correlating the $\mathrm{Hb}$ rise, with types of iron preparations given, showed $\mathrm{Hb}$ rise with, carbonyl Iron and iron sucrose were $0.914 \pm 0.20,2.43 \pm 0.20 \mathrm{gm} \%$ respectively, thus, clearly demonstrating the superiority of iron sucrose over the oral therapy ( $\mathrm{P}$ value $<0.001$, significant).

In the developed world, it has long been documented that intravenous iron supplementation is highly effective in treating IDA in pregnancy. There is irrefutable evidence that compared to oral iron, iv iron sucrose results in a much more rapid resolution of IDA, with minimal sideeffects, and also because it is administered intravenously, it circumvents the problems of compliance and absorption.

In present study also, there were minimal side effects with iron sucrose which were self-limiting. Anaphylaxis 
is highly unlikely as the complexes contain no biological polymers.

In this study, the side effects of iron sucrose could be completely avoided by dividing the total dose into smaller doses (100-200 mg/day) and by slow administration as seen in some studies by Al-Momen et al, Danielson BG and Hoigne et al. ${ }^{4-6}$

With regard to the mean haemoglobin rise, dramatic response was found in iron sucrose group as compared to oral iron group (both ferrous sulphate and carbonyl iron) as concluded by $\mathrm{Al}$ - Momen et al, that intravenous iron sucrose is safe, convenient and effective in pregnant women with IDA as compared to other oral iron preparation. Ample amount of data exists in India to show that supervised oral administration of upto $240 \mathrm{mg}$ iron has not been able to raise the $\mathrm{Hb}$ levels above $\operatorname{llgm} / \mathrm{dl}$ in pregnant women if their initial $\mathrm{Hb}$ levels was between 5.0 and $7.9 \mathrm{gm} / \mathrm{dl}$.

In present study, compliance with oral treatment was surprisingly good similar to a study conducted by Bayoumeu $\mathrm{F}$ et al in contrast to the findings described in some other studies. ${ }^{7}$ Gastrointestinal troubles, with a frequency of up to $30 \%$ as described by Al-Momen et al have been reported in patients groups treated with oral iron (carbonyl iron).Carbonyl iron showed a better rise in haemoglobin more than ferrous sulphate in a study conducted by Gordeuk et al. ${ }^{8}$

According to Kochchar PK et al, response to therapy with parenteral iron is similar to that with oral iron. ${ }^{9}$ The haemoglobin rises at a similar rate, although stores will be replenished more efficiently with parenteral iron (iron sucrose). The main advantage of parenteral therapy (iron sucrose) is the certainty of its administration to correct anaemia and build up the stores.

According to Perewusnyk $\mathrm{G}$ et al with his 8 years of experience with iron sucrose complex in twenty five countries indicated that Fe-sucrose complex therapy is a valid first-line option for safe and rapid reversal of $\mathrm{Fe}$ deficiency anaemia. ${ }^{10}$

\section{CONCLUSION}

The present study revealed that intravenous iron sucrose therapy was better tolerated with higher increase in mean haemoglobin when compared to oral iron therapy. There were no serious side effects with intravenous iron sucrose therapy. Intravenous iron sucrose is a good substitute to oral iron therapy in moderate anaemia.

Funding: No funding sources
Conflict of interest: None declared

Ethical approval: Not required

\section{REFERENCES}

1. Malviya MK, Bhardwaj VK, Chansoria M, Khare S. Anthropometric profile and perinatal outcome of babies born to young women (< 18 years). Indian Paediatr. 2003;40(10):971-6

2. Singh K, Fong YF, Arulkumaran S. Anaemia in pregnancy - a cross-sectional study in Singapore. Eur J Clin Nutr. 1998;52(1):65-70.

3. Wali A, Mustaq A, Nilofer (Aga Khan hospital for Women and Children, Kharadar, Karachi: A unit of Agha Khan Health Service, Pakistan). Comparative study - Efficacy, Safety and Compliance of Intravenous Iron Sucrose and Intramuscular Iron Sorbitol in Iron Deficiency Anaemia of Pregnancy. J Pak Med Assoc. 2002 Sep;52(9):392-5

4. Al-Momen AK, Huraib SO, Mitwalli AH, AlWakeel J, A1-Yamani M, Abu-Aisha H, Said R. Intravenous iron saccharate in hemodialysis patients receiving r-HuEPO. Saudi J Kidney Transplant 1994;5:168-72.

5. Danielson B. Intravenous iron therapy-efficacy and safety of iron sucrose. In Prevention and Management of Anaemia in Pregnancy and Postpartum Haemorrhage. 1998:93-106.

6. Hoigne R, Breymann C, Künzi UP, Brunner F. Parenteral iron therapy: problems and possible solutions. Schweizerische Medizinische Wochenschrift. 1998 Apr;128(14):528-35.

7. Bayoumeu F, Subiran-Buisset C, Baka NE, Legagneur H, Monnier-Barbarino P, Laxenaire MC. Iron therapy in iron deficiency anaemia in pregnancy: intravenous route versus oral route. Am J Obstet Gynecol. 2002;88:3-10

8. Gordeuk VR, Brittenham GM, Hughes MA, Keating LJ. Carbonyl iron for short term supplementation in female blood donors. Transfusion. 1987;27:80-5.

9. Kochhar PK, Kaundal A, Ghosh P. Intravenous iron sucrose versus oral iron in treatment of iron deficiency anemia in pregnancy: a randomized clinical trial. J Obstet Gynaecol Res. 2013 Feb 1;39(2):504-10.

10. Perewusnyk G, Huch R, Huch A, Breymann C. Parenteral iron therapy in obstetrics: 8 years experience with iron-sucrose complex. $\mathrm{Br} \mathrm{J}$ Nutr. 2002 Jul;88(1):3-10.

Cite this article as: Suganya G, Vimala D. A comparative study of oral iron and intravenous iron in iron deficient antenatal mothers. Int J Reprod Contracept Obstet Gynecol 2018;7:1848-51. 